\title{
Factors Affecting Scale Evolution of Hog Production ---- A Case Study of Santai County, Sichuan Province
}

\author{
Hongyun Han ${ }^{1}$, Xingyue Zeng ${ }^{2}$ \\ Center for Agriculture and Rural Development, Zhejiang University, Hangzhou, China \\ hongyunhan@zju.edu.cn
}

\begin{abstract}
Using field surveyed data of 144 hog producers in Sichuan province 2013, this paper aims to examine factors affecting evolution of farmers' hog production scale,.Regression results suggest that the farmers with capital advantages prefer larger scale than others. The capital include generations in the village, relatives in the government, family fixed assets, expericence of hog production and the costs for operation, whether join the cooperative, the distance from the highways, and land availability. To realize scale economy of hog production, it is necessary for the government to provide supports with more property and social capital to hold large scale hog farming and employ those who don't have the forementioned advantages. In addition, the government should design and build enough transportation facilities and ameliorate the circulation of rural land.
\end{abstract}

Index Terms - Scale evolution, Hog farming, Farmers' Behavior

\section{Introduction}

Hog production plays a critical role in Chinese farming. According to China Statistical Yearbo[1], the annual slaughtered hogs increased from 65,450,000 in 1952 to $667,000,000$ in 2010. China, as the largest hog producer, accounts for $50 \%$ of the world production. Large-scale farming is the future of Chinese hog farm (Deng Rong \& Zhang Cungen, 2008) [2]. To facilitate the hog production, the Chinese government issued a series of policy to support the evolution of large-scale farming. However, till 2010, the proportion of scale farms raising more than 500 heads hogs was $8.32 \%$ and the proportion of the hogs from those farms was $53.55 \%$. The development of scale farming is far behind that of U.S.A where the top 20 enterprises provide $70 \%$ of the hog production.

In China, most researches focus on factors affecting whether raise hogs, including internal and external factors. The internal factors include benefits of hog production, hog market in China, raising skills, costs for breeding and others, the quality of piglet and feed, the family characteristics as well as the ability to get loans and the land. The external factors include natural environments, policy of the government and the fluctuation of both the feeding and pork price (Fu Lai, 1994 [3]; Huang Delin etc., 2004 [4], Hu Hao, 2004 [5]; Zhou Shengli, 2005 [6]; Cao Yinghua, 2008 [7]; Zeng Jingjin, 2010 [8]). In addition, the chance for non-agricultural employment and the risks in anti-epidemic affect farmers' choices too (Deng Liqun, 2000 [9]; Yu Hua, 2007 [10]; Qi Ying, Lv Jie \& Song Lianxi, 2007 [11]). But no conclusion about how these factors affect the evolution of hog farmers' production scale. The key question is not whether, but how to facilitate the transformation of backyard farms into specialized household farms and how to assist large-scale farms and specialized household farms in integrating backyard farms into mainstream operations(Kevin Chen \& Jimin Wang, 2012 [12]). It is urgent to examine the factors affecting the hog farmers' production scale.

This paper aims to use the ordinal logistic regression model to deal with the data collected in Sichuan province so as to find out the factors which determine the farmers' hog production scale. The paper is organized as follows. After a brief introduction, section 2 is a description of the data and empirical analysis. Section 3 is an analysis of regression results. Conclusion are given in section 4.

\section{Data gathering and empirical analysis}

\section{A. Data}

The data of 144 farmers from 4 towns in Santai County, were collected in 2013 from field survey. Sicuhan is a typical base of hog production in China. However, only $50.17 \%$ of the production is from scale farms. The extent of the largescale hog farming is far behind other provinces, ranking the $24^{\text {th }}$. It is a phenomenon worthy of study (Feng Yonghui, 2006 [13]). Santai county was chosen as a study site because it was a demonstration city in hog producing and its yield ranks in the top cities, providing 1,893,000 heads in 2011.In total, 144 questionnaires were collected in Santai randomly selected sampled towns given in table 1. Each town gets the questionnaires as the same ratio of their hog yield.Farmers are also chosen randomly.

TABLE 1. Distribution of the questionnaires in 2011

\begin{tabular}{|l|c|c|c|c|}
\hline \multicolumn{1}{|c|}{ Items } & \multicolumn{4}{|c|}{ Towns } \\
\hline & Lixin & Luxi & Xiping & Liuying \\
\hline Stock & 49600 & 69300 & 62100 & 66900 \\
\hline Backyard & 4 & 5 & 5 & 16 \\
\hline Small & 3 & 4 & 3 & 12 \\
\hline Medium & 8 & 12 & 11 & 36 \\
\hline Large & 1 & 2 & 2 & 20 \\
\hline
\end{tabular}

\section{B. Empirical analysis}

Because we classified the production scale into 4 groups, we choose the ordinal logistic regression model to analyze those data. The 4 groups are Backyard, Small scale, Medium scale and large scale. The probability of them are $\pi_{1} 、 \pi_{2} 、 \pi_{3} 、 \pi_{4}$ respectively. We define the model as follows: 


$$
\begin{aligned}
& \left\{\begin{array}{l}
\operatorname{logit} \pi_{1} /\left(1-\pi_{1}\right)=\alpha_{1}+\sum_{1}^{n} \beta_{i} x_{i} \\
\operatorname{logit}\left(\pi_{1}+\pi_{2}\right) /\left[1-\left(\pi_{1}+\pi_{2}\right)\right]=\alpha_{2}+\sum_{1}^{n} \beta_{i} x_{i} \\
\operatorname{logit}\left(\pi_{1}+\pi_{2}+\pi_{3}\right) /\left[1-\left(\pi_{1}+\pi_{2}+\pi_{3}\right)\right]=\alpha_{3}+\sum_{1}^{n} \beta_{i} x_{i}
\end{array}\right. \\
& \left\{\begin{array}{l}
\pi_{1}=\exp \left(\alpha_{1}+\sum_{1}^{n} \beta_{i} x_{i}\right) /\left[1+\exp \left(\alpha_{1}+\sum_{1}^{n} \beta_{i} x_{i}\right)\right] ; \\
\pi_{2}=\exp \left(\alpha_{2}+\sum_{1}^{n} \beta_{i} x_{i}\right) /\left[1+\exp \left(\alpha_{2}+\sum_{1}^{n} \beta_{i} x_{i}\right)\right]-\pi_{1} \\
\pi_{3}=\exp \left(\alpha_{3}+\sum_{1}^{n} \beta_{i} x_{i}\right) /\left[1+\exp \left(\alpha_{3}+\sum_{1}^{n} \beta_{i} x_{i}\right)\right]-\pi_{1}-\pi_{2} ; \\
\pi_{4}=1-\pi_{1}-\pi_{2}-\pi_{3}
\end{array}\right.
\end{aligned}
$$

" $\alpha$ " is a constant indicating the intercept. " $\beta$ " is the coefficient of independent variable " $x$ ". Equation (1) is the natural logarithm of the ratio of the smaller scale level and the larger scale level. The ratio is called Odds Ratio (OR). If the $\mathrm{OR}>1$, the farmers would choose larger scale, otherwise, they would choose smaller one. Equation (2) can tell the probability of a farmer with given characteristics. The dependent variables can be classified as follow("g" means the yield of each farm):

$$
\left\{\begin{array}{l}
y=1, \quad g \leq 30 \\
y=2, \quad 30<g \leq 100 \\
y=3, \quad 100<g \leq 1000 \\
y=4,1000<g
\end{array}\right.
$$

\section{Results}

We use the SPSS software for the ordinal logistic regression and get a valid regression based on the chi-square test, -2 times the logarithm likelihood value and significance level. The results are given in table 2 .

The education was classified to 4 levels. The greater the education level is, the OR will be, which means farmers in higher education level prefer larger scale. But this independent variable is not significant; the education level does not have high correlation with scale evolution.

The history living in the village is also positive with a $1 \%$ level significance. When other conditions are fixed, one more generation makes the OR 2.10 times as before. The more generations a family living in the village can some how means the more social capital which promising more channel to get important information and more votes to get the right to use the land(Liu Zuyun \& Liu Min,2005 [14]). Table 3 indicates that most scale farmers choose the idle land and collective construction land to expand the scale.

Government relationship also contributes to a greater scale with a $1 \%$ level significance. When other conditions are

\begin{tabular}{|c|c|c|c|c|}
\hline Independent Variable & Items & Estimate & Std. Error & Sig. \\
\hline & Scale $=1$ & -3.113 & 2.459 & 0.206 \\
\hline & Scale $=2$ & 2.677 & 2.176 & 0.219 \\
\hline & Scale $=3$ & 21.245 & 5.413 & 0.000 \\
\hline \multirow{4}{*}{ Education $1,2,3,4$} & $x_{1}=1$ & -4.905 & 2.029 & 0.016 \\
\hline & $x_{1}=2$ & -2.794 & 1.904 & 0.142 \\
\hline & $x_{1}=3$ & -2.706 & 2.004 & 0.177 \\
\hline & $x_{1}=4$ & $0 \mathrm{a}$ & . & . \\
\hline Fixed assets [Million yuan] & $x_{2}$ & 0.101 & 0.033 & 0.002 \\
\hline Generations in the village & $x_{3}$ & 0.743 & 0.267 & 0.005 \\
\hline Relatives in government & $x_{4}$ & 0.368 & 0.238 & 0.098 \\
\hline Distance from highway & $x_{5}$ & -0.890 & 0.369 & 0.016 \\
\hline \multirow{2}{*}{ Whether Join Co-op } & $x_{6}=0$ & -1.438 & 0.920 & 0.118 \\
\hline & $x_{6}=1$ & $0 \mathrm{a}$ & . & . \\
\hline Duration[Year] & $x_{7}$ & -0.208 & 0.067 & 0.002 \\
\hline \multirow{5}{*}{ Access to Land } & $x_{8}=1$ & 4.632 & 3.125 & 0.138 \\
\hline & $x_{8}=2$ & -2.229 & 2.057 & 0.278 \\
\hline & $x_{8}=3$ & -4.689 & 1.903 & 0.014 \\
\hline & $x_{8}=4$ & 4.204 & 3.307 & 0.204 \\
\hline & $x_{8}=5$ & $0 \mathrm{a}$ & . & . \\
\hline Gov. Subsidy Ratio & $x_{9}$ & 6.432 & 2.388 & 0.007 \\
\hline Operation Money[Yuan ] & $x_{10}$ & $6.788 \mathrm{E}-5$ & $1.691 \mathrm{E}-5$ & 0.000 \\
\hline Ratio of money from others & $x_{11}$ & 1.233 & 1.403 & .379 \\
\hline
\end{tabular}
fixed, one more relative in government, the OR will be 1.445 times as before. Relatives in government is a kind of social capital which can bring the farmer more policy information

\begin{tabular}{|c|c|c|c|c|}
\hline \multirow[t]{2}{*}{ Items } & \multicolumn{4}{|c|}{ Size classification } \\
\hline & Backyard & Small & Medium & Large \\
\hline Total Samples & 30 & 22 & 67 & 25 \\
\hline Ratio in Cooperative & 0 & $31.82 \%$ & $47.76 \%$ & $52 \%$ \\
\hline $\begin{array}{l}\text { Access to land(Ratio) } \\
1=\text { Idle land } \\
2=\text { Homestead land } \\
3=\text { Collective construction } \\
4=\text { Rent others' farm land } \\
5=\text { Others }\end{array}$ & $\begin{array}{l}26.67 \% \\
50 \% \\
20 \% \\
3.33 \% \\
0\end{array}$ & $\begin{array}{l}54.54 \% \\
22.73 \% \\
22.73 \% \\
0 \\
0\end{array}$ & $\begin{array}{l}56.72 \% \\
8.96 \% \\
17.91 \% \\
1.49 \% \\
14.92 \%\end{array}$ & $\begin{array}{l}80 \% \\
0 \\
0 \\
0 \\
20 \%\end{array}$ \\
\hline
\end{tabular}
and application convenience (Liu Zuyun \& Liu Min,2005 [14]).
TABLE 2. Regression Results

a. Detailed choices of Access to land are in Table 3

TABLE 3. Average characteristics of samples

As expected, distance from the highway decides the transportation convenience which can affect the production scale. Per unit increasing in the distance will make the OR 0.411 times as before. The variable is significant in a $5 \%$ level. 
Whether the farmers join in the cooperative organization seems to affect farmers' choice too. The OR of farmers who don't join in the cooperative organization is 0.237 times as those who do. As the survey shows, cooperative organizations offer the members various service such as discount for buying feed, a higher purchasing price for hogs, some trainings and epidemic prevention. However, there are some limitations for the members, such as that only those who raise more than 50 head hogs per year can join in the cooperative organization. So we get the results that none backyard farmers join in the organization. We can see from Table 3 that the larger scale farm has a higher ratio of farmers joining in the organization. Although we can't decide whether it is the reason causing larger scale farming, we can see that cooperative organization indeed contribute to the scale farmers. During the survey we also get a local statistical data that about $30 \%$ farmers would like to enlarge their scale in order to get the service in the cooperative organization.

Actually, the duration of the farmers being in the hog production also affects their decisions. Before the survey we assume that the longer their experience of raising hogs, the larger farm scale they would choose. But the regression results show that one more year experience makes the OR 0.812 times as before. According to the survey, some small or medium scale farms have existed for only 5-8 years, mainly because of promotion policy in 2007,2008 and 2009. The government gave subsides to the farmers who built scale hog farms. The farmers' average ages of small scale and the medium one are 35.33 and 43.14 respectively. About $40 \%$ of them are returning migrant workers. They are good at learning new skills and more sensitive to the market. The most important thing is that they hope to stay in the hometown and highly demand for entrepreneurial opportunities. That is why they have less experience but larger scale.

Land availability is a disorder classification variable. So the estimate of each choice is disordered. When other conditions are fixed. Choice 1 or choice 4 would cause the OR 102.72 or 66.95 times as choice 5.In other words that means if farmers get land through choice 1 and choice 4, they would prefer lager production scale than choice 5 .It can also be seen in Table 3 that lager scale with bigger proportion in choice 1.However, compared with choice 5 , choice 2 or choice 3 will make the OR 0.11 or 0.009 . So if farmers get land from choice 2 or 3, they would prefer smaller scale. Ratio of choices in Table 3 can explain the results. Actually in the research sites idle land or rented land can promise lager area than homestead land or collective construction land.

However, the subsidy ratio from the government is significant in a $1 \%$ level. per unit increase in the subsidy ratio will make the OR 641.41 times as before. In other words, government subsidy is an important factor to the farmers. Here the subsidy means the money for farm construction fees, not the subsidy for sows, epidemic prevention or insurance. Because the later ones are subsidies for each animal, how much you can get depends on the heads you are raising. More subsidies means higher cost either. So the later ones means less to farmers. But the subsidy for construction means a lot, because it depends on the scale of the farm, the more the better. For example, in 2007, there was a subsidy project for residential construction. Those who built a hog farm more than $70 \mathrm{~m}^{2}$, can get 80 yuan for each square meter. Actually the subsidy is about $1 / 3$ of the whole construction fees which saved the farmers a lot start-up cost. According to the officials, the subsidy policy was canceled in 2011 and 2012, so farmers applying for building or expanding farms are about $30 \%$ less than before. Certainly, it may also result from the saturation of hog farms. But it is undeniable that such subsidy gives farmers a lot of encouragement.

The importance of subsidy is also reflected in the operation money which is also significant in a $1 \%$ level. Every unit increase in money will change the OR 6.788E-5times as before. As we all know, the operation money can pay for the variable cost. So more money may lead to scale effect, otherwise it may waste some fixed cost. But where the money comes from does not affect too much, because the variable is non-significant.

\section{Conclusion}

Regression results indicate that farmers with more social capital and fixed assets will choose larger production scale. Namely, having more generations in that village, more relatives in government, more fixed assets and more operating money all will cause larger scale farming. In addition, cooperative organization as a service platform for scale farming, may also encourage farmers to expand the scale. However the distance from the highway and the years they have been in hog production may be factors hindering the development of scale farming.

Following measures should be considered to provide necessary supports for the scale evolution of hog production:

Capital support is necessary to encourage farmers to set up large scale hog farms or establish cooperative organizations.

It is critical to provide necessary public facilities like highways. That may promise the farmers' transportation of buying feed and selling products.

Last but not least, it is needed to reform land circulation policy, because it can make those who have efficient producing ideas get enough land they need.

\section{References}

[1] 2011 China Statistical Yearbook

[2] D. Rong, Z. Cungen, "Study on Sustainable Development of Animal Husbandry in China," Agricultural Outlook, vol.4 (10), pp. 37-39, 2008.

[3] F. Lai, "On the Drastic Decline of Hog Production," Problems of Agricultural Economy, vol.15 (8), pp.29-32, 1994.

[4] H. Delin, X. Enbo, Z. Shaofeng, C. Yuhua and L. Zhongdong, "Chinese Hog Farmers' Producing Behavior Characteristics," Shanxi Journal of Agricultural Sciences, vol.12, pp.20-23, 2004.

[5] H. Hao, "Analysis of Management Forms of China's Hog Production at Present," Chinese Rural Economy vol.40(11), pp.28-31, 2004.

[6] Z. Shengli. "Study on the development of China's Hog Producing Industry," Doctoral dissertation, Central China Agricultural University, in Hubei China, 2005 
[7] C. Yinhua, "The Hog Production's Situation in Hunan and Its development tasks in the future," Swine industry economics, vol.3(5), pp.28-30, 2008.

[8] Z. Jingjin, "Factors affecting the farmers' desire to raise hogs, take farmers in Jiangshan Zhejiang province as an example," Acta Agriculture Jiangxi, vol.22 (4), pp.156-158, 2010.

[9] D. Liqun, "Study on the hog production in Nanjing and the factor affecting the production," Master's Dissertation, Nanjing Agricultural University, in Nanjing China, 2000.

[10] Y. Hua, "The Investigation and Reconsideration about the Present Situation of the Live Pig Industry," Marketing Research, vol.7, pp. 2123, 2007.
[11] Q. Ying, L. Jie and S. Lianxi, "Economic Analysis of Fluctuations in the Price of Live Pigs," Chinese Journal of Animal Science, vol.43(2), pp.31-35, 2007.

[12] C. Kevin, and J. Wang. "Hog farming in transition: The case of China." Asian livestock, vol.16, pp.73-80, 2012.

[13] F. Yonghui, "The Scale Hog Production of China and The Changing Trend of Its Reginal Distribution," Chinese Journal of Animal Science, vol.42 (4), pp.22-26, 2006

[14] L. Zuyun, Liu Min, "A Research Review of The Relationship Between The socioeconomic status of Fluid Farmers and Human and Social Capital,” Social Science Research,vol.6, pp.118-123, 2005 